\title{
SI È APERTA UNA PORTA CON DIETRO IL BUIO: APONTAMENTOS SOBRE O FILME LA Rabbia, de Pier Paolo Pasolini
}

\author{
JULIA SCAMPARIN *
}

RESUMO: Este ensaio sobre o filme La rabbia (1962), de Pasolini, dialoga com um momento histórico de muita produtividade de documentários ensaísticos e de análises e teorias a respeito. O olhar direcionado ao passado procura, então, atualizar-se por meio de escritos contemporâneos, e promove um encontro com o recente gesto de restauração e redescoberta de um filme desejado, mas não finalizado décadas atrás. Todo este contexto de análise e revisitação deixa claro que o filme La rabbia tem a raiva como sua espinha dorsal, antes, durante e depois: o sentimento poético-político da raiva que impulsiona o gesto artístico, como é de costume em Pasolini; a raiva pela matéria-prima, as imagens-inimigas, parte da metodologia de trabalho; e, finalmente, a raiva pela imposição do produtor e pelo embate indesejado com um opositor ideológico, após ter em mãos o filme pronto.

PALAVRAS-CHAVE: Cinema Italiano; filme-ensaio; documentário; Pier Paolo Pasolini

ABSTRACT: Questo saggio sul film La rabbia (1962), di Pasolini, dialoga con un momento storico ricco di produzione di documentari saggistici e di analisi teoriche e teorie in proposito. Lo sguardo volto al passato cerca, allora, di aggiornarsi mediante scritti contemporanei, e favorisce un incontro con la recente proposta di restauro e riscoperta di un film desiderato, ma non finito decenni fa. Questo contesto di analisi e rivisitazione chiarisce che il film La rabbia ha la rabbia come spina dorsale, prima, durante e dopo: il sentimento poetico-politico della rabbia che spinge al gesto artistico, come è consueto in Pasolini; la rabbia della materia prima, le immagini-nemiche, parte della metodologia di lavoro; e, finalmente, la rabbia per l'imposizione del produttore e per l'indesiderato scontro con un avversario ideologico, dopo aver finito il film.

PAROLE CHIAVE: cinema italiano; film-saggio; documentario; Pier Paolo Pasolini

*Universidade Estadual do Rio de Janeiro (Brasil)

juliascamparini@gmail.com

http://dx.doi.org/10.11606/issn.2238-8281.v0i39p4-13 
ABSTRACT: This essay about La rabbia (1962) a film by Pier Paolo Pasolini, belongs to a historical moment in which the production of essay documentaries is fruitful, as well as theories and analysis about them. This review intends to dialogue with contemporary writings and also with the re-production of La rabbia decades later, a restoration of what Pasolini would have wanted. Our choices have shown a structure in which anger is the vertebral column of the film before, during its creation, and after: the poetic and political feeling that made the film possible; the enemy-images and Pasolini's hate towards them; and finally a possible feeling of anger after the imposition of the producer of La rabbia, who included another author - an ideological opponent - for the second part of the film.

KEY-WORDS: Italian cinema; essay film; documentary; Pier Paolo Pasolini. 


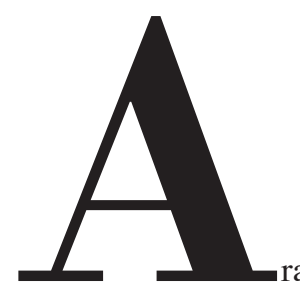

raiva de Pasolini é muito bem localizada e direcionada: está exposta em seus romances, poemas, filmes, entrevistas, crônicas, críticas, teorias. A raiva de Pasolini, que serve de título a seu quarto filme, La rabbia, não é somente reação à época e à sociedade em que viveu, mas deve ser tomada, sobretudo, como postura poético-política, um conceito que define uma indignação produtiva e indissociável da atuação crítica de um artista. Para ele, os raivosos são tão necessários para o desenrolar da história quanto os revolucionários:

A contestação do raivoso é interna ao sistema, pede a modificação do sistema para que o mesmo viva. O revolucionário, ao contrário, nega o sistema e a ele contrapõe uma perspectiva utópica. [...] muito frequentemente o revolucionário, depois de ter destruído a sociedade constituída, excede em sua reconstrução, quer que tenha novamente todos os atributos, até mesmo o moralismo e o perbenismo burguês, enquanto o raivoso, às vezes, incide mais profundamente que o revolucionário ${ }^{1}$ (PASOLINI, 2013, p. 176).

Antes mesmo da entrevista em que consta o trecho acima, de 1966, posterior ao lançamento de La rabbia, as declarações e produções pasolinianas delineavam o sentido de raiva como conceito combustível para a criação. O trecho abaixo pertence ao belíssimo texto que serve de argumento para o filme La rabbia, publicado em 1962. Nesse texto de apresentação, Pasolini defende que contra o estado de normalidade é preciso criar o estado de emergência, e é aí que entra em questão o artista raivoso:

No estado de normalidade não se olha o entorno: tudo ao redor se apresenta como normal, sem a excitação e a emoção dos anos de emergência. $O$ homem tende a adormentar-se na própria normalidade, esquece de refletir, perde o hábito de julgar a si mesmo, não sabe mais se perguntar quem é. É neste momento que deve ser criado, artificialmente, o estado de emergência. E é papel dos poetas criá-lo. Os poetas, esses eternos indignados, esses defensores da raiva intelectual, da fúria filosófica. (PASOLINI, 2009, p. 13)

Pasolini realiza La rabbia no início dos anos 1960, após a guerra e após o pós-guerra, provocando os ânimos de uma época extremamente cansada. Naquele momento, uma espécie de noite de sono tão desejada e comum a todos, Pasolini acendeu a luz e mostrou que o pesadelo não acabara, mas estava disfarçado pela aparente calmaria de um céu estrelado. Foi o sentimento poético-político da raiva que motivou o projeto a ser realizado, tornou-se metodologia de trabalho e, finalmente, surgiu como recusa, após ter em mãos o filme pronto. Antes, durante 
e depois. Talvez por isso, o que mais se conheça sobre esta espécie de ensaio que é o filme $L a$ rabbia sejam as histórias contadas sobre ele, mais do que o próprio filme.

A convite de um pequeno produtor, Gastone Ferranti, Pasolini aceita se debruçar sobre 90 mil metros de película produzidas para o cinejornal semanal Mondo libero, do mesmo produtor, reunidas durante quase dez anos, de 1953 a 1962. Desses muitos metros de película, Pasolini deveria selecionar e remontar sequências, criando um discurso próprio, em que estivessem claras suas condutas ideológica e poética. Após já ter realizado Accattone e Mamma Roma e estar envolvido na produção de La Ricotta, o convite é uma oportunidade nova de criação: imagens desprovidas de qualquer estatuto artístico, destinadas à informação, sem voz, submetidas a um discurso de poder, deveriam ser remontadas pelo gesto político de dar a elas um viés crítico.

O gênero do cinejornal é, segundo Bertolucci, "o mais baixo, o mais exposto às piores derivas qualunquistas, e Pasolini o revisita aceitando "sujar as mãos no estrume para dele extrair pedras preciosas de algumas imagens extraordinárias" (BERTOLUCCI, 2009, p. 219). Essas imagens valiosas se tornarão, nas mãos e palavras de Pasolini, "o sorriso de um desconhecido, dois olhos com expressão de alegria e dor, sequências interessantes cheias de significado histórico." (2009, p. 7). Para ele, a operação criaria um novo gênero, seria "um ensaio ideológico e poético com sequências novas" (idem), e La rabbia, o primeiro filme deste intencional novo gênero, se voltaria:

contra a irrealidade de um mundo burguês e sua consequente irresponsabilidade histórica... para documentar a presença de um mundo que [ao contrário do mundo burguês] possui profundamente a realidade. A realidade, ou seja, um amor verdadeiro pela tradição que só a revolução pode produzir (PASOLINI 2009, p. 7, itálico meu).

Esta "performance metalinguística" (nas palavras de Giuseppe Bertolucci) foi, portanto, resultado de um encontro com um novo dispositivo de se fazer cinema. Ausente na confecção de uma das etapas da montagem, que é a das filmagens, o que Pasolini faz com a etapa crucial da montagem, aquela de corte e colagem - maior responsável pelo que diz um filme, segundo sua própria teoria cinematográfica -, é o bastante para garantir a potência de uma obra em que a palavra, em forma de poesia e prosa, são os elementos escolhidos para ressignificar a História. Pasolini debutava como ensaísta cinematográfico.

Da perspectiva cinematográfica, a forma ensaio carece de fronteiras definitivas, mas pode ser definida como "uma prática que reconhece, nas imagens, singularidades que não podem ser lidas de outra forma sem uma significativa perda de seus referenciais" (COMOLLI, 2008, p. 152), ou como uma "máquina de pensamento, meio de uma reflexão sobre a imagem e o mundo, que traduz experiências, imprime rupturas, resgata continuidades" (LINS et al, 2011, p. 58). No interior das discussões e tentativas de definição sobre o filme-ensaio, é central o tema da apropriação de imagens, uma operação muito frequente no documentário contemporâneo, mas que já nos anos 1950 e 1960 representava o diferencial de cineastas ensaístas como, por 
exemplo, Chris Marker e Godard.

Apropriar-se de imagens de arquivo, já usadas e fadadas ao esquecimento, significava (e significa) não só mudar o olhar que as produziu, mas recuperá-lo também, antes de mais nada. No entanto, no caso do material de arquivo disponibilizado a Pasolini, a autoria era incerta, trabalho de cinegrafistas possivelmente inconscientes do peso de suas escolhas, ou mesmo certos de que suas escolhas respondiam a um posicionamento acrítico, pacificador. Ao lado do anonimato da autoria, havia também o olhar que a elas se voltara, mediado e subtraído pela forma noticiário: em um cinejornal tradicional estavam ausentes as entrevistas e os planos médios, enquanto os vídeos, quase sempre sem o áudio original, eram comentados por uma mesma voz off e introduzidos por um fotograma fixo com o título da notícia. Um único comentário musical sublinhava o gênero e se mantinha ao fundo por toda a duração.

Produzidas por outros e destinadas ao consumo de um público específico, as imagens do material bruto de cinejornais são, portanto, para um cineasta como Pasolini, imagens-inimigas. Mas seu gesto é o de aceitar que tais imagens se apresentam como um campo de conflitos passível de novas leituras, e não são um objeto com uma substância dada, fixa. Assim, procurará nelas uma forma de ir contra a "irrealidade do mundo burguês" reconstruindo-as discursivamente, de forma a redimensioná-las para devolvê-las ao mundo. Sua concepção de realidade (amor verdadeiro pela tradição), contudo, não se limitou a encontrar nas imagens vestígios do mundo arcaico em que enxerga valor, verdade, vida; ao contrário, sua fome de realidade (não de realismo) encontrou-se com sua excepcional teoria do que é o cinema. Para Pasolini, a imagem cinematográfica equivaleria à língua escrita, assim como a realidade equivaleria à fala. Se para ele realidade e fala são potências, língua escrita e cinema são atos (PASOLINI, 2005). Diante disso, o papel do artista é o de produzir narrativas críticas, discursos outros, ou seja, atos que se distanciem seja do que as palavras portam de simbólico como daquilo que as imagens carregam de convencional.

Assim, o feito de Pasolini foi o de rever tais imagens a partir de seu interior, pensando-as, interrogando-as, interpretando-as, descrevendo relações, criando dialogismos, sem perder de vista sua história. Estamos na década de 1960, época em que a Itália estava deixando de ser um país agrícola e se tornando industrial, momento em que Pasolini enxergou a virada irreversível que culminaria na padronização dos anseios e comportamentos (AMOROSO, 2002). É a época em que a nova tecnologia era a televisão, que chegaria já mudando nossa percepção do mundo, massificando opiniões, tornando as imagens mais do que nunca sujeitas aos discursos institucionais, destacadas de seus referentes e despojadas de sua possível potencialidade.

No roteiro de La rabbia, o episódio sobre a televisão diz:

[as redes televisivas] Experimentam formas de dividir a verdade e apresentar a meia verdade que sobra através da única voz que a burguesia tem para usar: a voz que contrapõe uma ironia humilhante a todo e qualquer ideal, a voz que contrapõe piadas à Tragédia, a voz que contrapõe o bom senso dos assassinos aos excessos do homem bom. 
Por enquanto somente quatro mil assinantes têm o telecinema em casa: em um ano serão dezenas de milhares.

Não. Serão milhões. Milhões de candidatos à morte da alma (PASOLINI, 2009, p. 50).

Pasolini inicia seu filme com imagens de guerra, morte e miséria humana, como as da Revolução Húngara de 1956, optando por ser um comentador dos graves acontecimentos da época sem se dobrar a uma cronologia imposta pelo material fornecido. O recorte é temporal, mas as sequências não obedecem a esta ordem. É desta forma que Pasolini escolhe oferecer as outras metades da verdade narrativizada pelos meios de comunicação de massa, alternando textos em prosa que apresentam os eventos, muitas vezes com um tom carregado de ironia, e poemas quase sempre acompanhados por música, lidos pelo artista plástico Renato Guttuso. Assim, as agressivas manifestações anticomunistas nas capitais europeias são esvaziadas de um real significado pela poesia de Pasolini:

Se não se grita viva a liberdade humildemente, não se grita viva a liberdade. Se não se grita viva a liberdade sorrindo, não se grita viva a liberdade. Se não se grita viva a liberdade com amor, não se grita viva a liberdade. Vocês, filhos dos filhos, gritam com desprezo, com raiva, com ódio, viva a liberdade, por isso não gritam viva a liberdade [...] (PASOLINI, 2009, p. 60)

E as investidas neocolonialistas contemporâneas às tantas guerras pela independência de países como Cuba ou os africanos são acontecimentos lidos de modo lúcido e visionário, de forma a oferecer análises sobre o mundo que até hoje se mantêm atuais:

Surge um novo problema no mundo. Chama-se Cor. Chama-se Cor a nova extensão do mundo. Precisamos incorporar a ideia de milhares de filhos negros ou marrons, crianças com os olhos negros e cabelo pixaim. Precisamos aceitar superfícies infinitas de vidas reais, que querem, com inocente ferocidade, entrar na nossa realidade. Outras vozes, outros olhares, outros amores, outras danças: tudo terá que se tornar familiar e engrandecer a terra! (PASOLINI, 2009, p. 78).

Ao realizar um documentário, segundo nos diz Comolli (2008, p. 153):

[...] filmamos também algo que não é visível, filmável, não é feito para o filme, não está ao nosso alcance, mas que se encontra lá com o resto, dissimulado pela própria luz ou cegado por ela, ao lado do visível, sob ele, fora do campo, fora da imagem, mas presente nos corpos e entre eles, nas palavras e entre elas, em todo o tecido que trama a máquina cinematográfica. Filmar os homens reais no mundo real representa estar tomado pela desordem dos modos de vida, pelo indizível das vicissitudes do mundo, aquilo que do real se obstina a enganar as previsões. Impossibilidade do roteiro. Necessidade do documentário.

La rabbia não é um documentário e precisou de um roteiro, mas a citação de Comolli elucida a tarefa a que se propôs o cineasta que deu àquelas imagens um discurso alternativo. 
Pasolini conseguiu ver o que estava ao lado do imediatamente visível, isto é, propôs que se enxergassem possíveis, devires, existências que ali estavam, mas que não eram (são) vistas, pois não pertenciam (pertencem) ao regime de coisas visíveis a que estamos submetidos. As operações de seleção e combinação das imagens buscaram dar a elas a voz que o jornalismo naturalmente lhes tira, transformando as pessoas retratadas de objetos em sujeitos, e ofereceram a esses sujeitos uma narrativa alternativa. Pasolini quis inscrevê-los na História, recuperar sua presença nas imagens e trazê-las para o discurso, restituindo seu corpo-na-imagem.

Para fazê-lo, Pasolini produziu um discurso distinto que contemplou, no mínimo, dois textos: as partes em prosa retomam os fatos históricos e os reescrevem, e a poesia sobrepõe uma camada de lirismo aos sujeitos, eventos e lugares recuperados nas imagens. Como diz Amoroso, Pasolini “não dessacraliza o mundo; o que faz é ressacralizá-lo, alterando, porém, os lugares e as coisas que usualmente são considerados sagrados, como já fizera, aliás, em Accattone e A ricota". (2002, p. 54)

Com La rabbia, Pasolini fez sua primeira investida cinematográfica no Outro, um outro não italiano, não europeu, pertencente a sociedades mais primitivas, onde reconhece sua paixão. Não à toa que nos anos seguintes realizará obras documentais e ficcionais ancoradas nessas sociedades. Este Outro que normalmente não tem voz, não tem psicologia, seja nas imagens-inimigas, como na própria História. Ao analisar o uso da subjetiva indireta livre por Pasolini, Ismail Xavier explica que:

[...] o tipo de experiência, mundo interior, que o discurso indireto livre põe como mediação para a percepção das coisas é a experiência, o estilo de percepção, de alguém que é portador de uma cultura estranha à da plateia. Tal portador está ali para afirmar uma diferença; representa uma alteridade, o confronto entre passado (mundo arcaico do mito, experiência da natureza própria ao camponês) e presente (sociedade burguesa técnico-urbana). Como resultado, a invenção estilístico-formal passa a ter um correlato de tipo antropológico (código cultural do Outro, referência a uma vivência coletiva do mundo).

As outras civilizações não são somente as africanas, Cuba ou Índia, mas são também “outras civilizações" o sub-proletariado, os Accattones, Mammas Roma e Stracci urbanos, e também os sertanejos, suburbanos ou favelados, se trouxermos o olhar pasoliniano mais para perto.

Após terminado o filme, Pasolini recebe a notícia de que nele haveria uma segunda parte, dirigida por um de seus opositores ideológicos, Giovannino Guareschi. Guareschi era escritor, jornalista e humorista, um "poeta vendido", o contrário absoluto dos raivosos, estes sim, verdadeiros artistas, segundo Pasolini. Com sua parte já pronta, Pasolini aceita não só dividir o filme com o opositor, como também abre mão dos 16 minutos inicias, justamente aqueles mais italianos, com imagens do funeral de De Gasperi, paisagens da Itália e cenas da televisão italiana, entre outros eventos. O embate entre os dois autores passou a ser o mote do filme, que se abre com a seguinte chamada: Duas ideologias de tendências opostas respondem a uma dramática 
interrogação: Por que a nossa vida é dominada pelo descontentamento, pela angústia, pelo medo da guerra, pela guerra?

La rabbia parece ter, portanto, a raiva como espinha dorsal antes, durante e depois: a raiva que impulsiona o gesto artístico, como lhe é de costume; a raiva pela matéria-prima, as imagens-inimigas; e, finalmente, a raiva pela imposição do produtor e pelo embate indesejado com um opositor ideológico.

O filme La rabbia, de Pasolini e Guareschi, não teve destinatários. Foi lançado em 1963 e, quase sem público, foi tirado de cartaz e esquecido. Hoje pode ser facilmente encontrado na rede, mas são poucos os trabalhos a ele dedicados, talvez por estar ainda assombrado pela crítica de então, majoritariamente negativa, além de rara. Mas em 2008, em um impulso de historiador, orientado a salvaguardar toda a contribuição artística e o pensamento de Pasolini, Tati Sanguinetti tem a ideia de reconstituir os 16 minutos imaginados pelo poeta, e propõe ao cineasta Giuseppe Bertolucci a incumbência de curar a inserção das cenas do arquivo do "Istituto Luce" a partir do roteiro pasoliniano, publicado em Per il cinema, da Mondadori (2001). Hoje existe, portanto, o filme La rabbia di Pasolini - un'ipotesi di ricostruzione, de 83 minutos, lançado em 2008, no Festival de Veneza, em sua inteireza, como desejara há mais de 50 anos nosso poeta raivoso.

Ao final do roteiro de La rabbia, em Per il cinema, há um adendo, que ainda não descobri se é um roteiro não filmado, ou se é um curtíssimo filme que se encontra perdido em algum lugar. É chamado Resposta a Guareschi e diz:

Excelentíssimo Guareschi, (imagem de Guareschi fotografado)

como todo humorista que se respeite - e eu quero respeitá-lo - o senhor é um reacionário.

(imagem de um monumento aos mortos de guerra)

Por isso sei bem qual será a sua raiva, a sua raiva reacionária...

(imagem de um filme de Fernandel, que ri)

será a raiva de quem vê o mundo mudar, isto é, fugir-lhe, porque os reacionários são doentes, espíritos sem pés.

(lançamento de um míssil)

Sei bem quem será exaltado e quem será humilhado em seu filme nestes últimos dez anos de história e de nossa vida.

(rosto de gente exaltada e gente humilhada no filme de Guareschi)

O senhor está na direita, defendendo as instituições, porque tem medo da história.

Os monumentos não são perigosos. No máximo, são feios. E o senhor é insensível à 
feiura.

(imagem do monumento ao Soldado Desconhecido talvez com uma cerimônia...)

O senhor é insensível à feiura. Por isso escolheu a mediocridade.

(imagem das capas dos livros de Guareschi)

É esta a razão pela qual, se eu o respeito como humorista, o respeito menos como escritor.

(imagem de uma vinheta de Guareschi, e das capas dos livros de Guareschi em francês e inglês)

E exatamente porque o senhor usará as armas da mediocridade, do qualunquismo, da demagogia e do bom senso, o senhor será vencedor dessa nossa polêmica, eu bem sei.

(enquadramento demagógico de Cervi no papel de Peppone - Imagem de gente que aplaude)

Mas qual é a verdadeira vitória, aquela que faz bater palmas ou aquela que faz bater os corações? (PASOLINI, 2001, p. 412-413)

Finalmente, retomo a frase que dá título a este texto: Si è aperta una porta con dietro il buio. Ela não se refere exatamente ao filme, e não foi dita por Pasolini, mas por um de seus entrevistadores, em 1966. Mas essa frase, abrir uma porta e ver atrás dela a escuridão, parece-me, traduz o grande paradoxo vivido por Pasolini durante toda sua vida. 


\section{Referências}

AMOROSO, Maria Betania. Pier Paolo Pasolini. São Paulo: Cosac Naify, 2002.

BERTOLUCCI, Giuseppe. Note sul film La rabbia di Pasolini (2008). In CHIESI, Roberto (cur), PASOLINI, Pier Paolo. La rabbia. Bologna: Edizioni Cineteca di Bologna, 2009.

CHIESI, Roberto (cur), PASOLINI, Pier Paolo. La rabbia. Bologna: Edizioni Cineteca di Bologna, 2009.

COMMOLI, Jean-Louis. Como filmar o inimigo. Ver e poder, a inocência perdida: cinema, televisão, ficção, documentário. Belo Horizonte: Ed. UFMG, 2008.

DUFLOT, Jean (org), PASOLINI, Pier Paolo. As últimas palavras do herege. São Paulo: Brasiliense, 1983.

LINS, Consuelo; REZENDE, Luiz Augusto; FRANÇA, Andréa. A noção de documento e a apropriação de imagens de arquivo no documentário ensaístico contemporâneo. Revista Galáxia, São Paulo, n. 21, p. 54-67, jun. 2011.

MÜLLER, Adalberto. A semiologia selvagem de Pasolini. Devires, Belo Horizonte, v.3, n.1, p.88105, jan-dez. 2006.

PASOLINI, Pier Paolo. Uno dei rari arrabbiati italiani. In Povera Italia: interviste e interventi, 19491975. Milano: Kaos edizioni, 2013. . La lingua scritta della realtà. In Empirismo eretico. Milano: Garzanti, 2005.

Mondadori, 2001.

Appendice a "La rabbia"; "Confessioni tecniche" e altro. In Per il cinema. Milano:

\& GUARESCHI, G. La rabbia [Streaming]. Itália: Gastone Ferranti, 1962.

XAVIER, Ismail. O cinema moderno segundo Pasolini. Revista Italianística, São Paulo, n. 1, p. 101$109,1993$.

Recebido: 30/08/2019

Aprovado: 27/11/2019 